HORTICULTURE

\title{
Effect of Tea as a Potting Substrate on Germination and Seedling Growth of Papaya Seeds
}

\author{
Paromita Mandal and Ankan Das*
}

Department of Horticulture, Institute of Agricultural Science, University of Calcutta, Kolkata, West Bengal, India

"Corresponding author: ankandas660@gmail.com (ORCID ID: 0000-0002-0946-2653)

Paper No. 936

Received: 27-08-2021

Revised: 22-11-2021

Accepted: $13-12-2021$

\begin{abstract}
Papaya is one of the most important fruit crop. It is grown in tropical to sub tropical areas all over the world and is mainly propagated by seeds which show wide variability in germination and seedling growth. The experiment was conducted to find out the "effect of tea as a potting substrate on germination and seedling growth of papaya seeds.". Tea was used as a substrate in this experiment. Tea can improve soil porosity, density and soil nutrient and helps to suppress plant disease because it is comprised of microbes, humic acid, nitrogen, carbon etc. Total six treatments comprising of 100, 80, 70, 60, 50 and $0 \%$ of tea were placed in Completely Randomized Design. There were three replications for each of the six treatments, which were put in pots having the combination of growing media. Observations were taken at different day's interval from sowing. In terms of plant parameters significant difference was observed from $3^{\text {rd }}, 4^{\text {th }}$ and $5^{\text {th }}$ week after emergence. In overall it was obtained that 60 and $50 \%$ of tea was most effective medium for papaya seedling production.
\end{abstract}

\section{HIGHLIGHTS}

(0 Tea when used as a potting substrate at 60 and 50\% in combination with soil had desirable positive impact on growth of papaya seedlings.

Keywords: Papaya, seed, tea, planting, attributes

The fruit of papaya is very lucrative and is also called as the fruit of wonders in the tropical regions (Rana et al. 2020). The fruit is a stack house of innumerable nutrients. It is highly rich in vitamin A and contains significant amount of vitamin B2 and many other nutrients (Rana et al. 2020). The crop of papaya is mainly developed through seed, however the problem which lies here is that the seeds after picking, enters a phase of retrogression which hampers the germination and plant development. This phenomenon is mainly because of assemblage of some growth inhibitors in the saecotesta of the seed, during the period of storage (Pandit et al. 2001; Reyes et al. 1980).

The process of germination of seed is an exercise where the embryo present, starts developing into a juvenile plant. However it is not true for all seeds, as there are some which at suitable situation also resists the process. This dormancy may be of many causes, like hard seed coat, germination inhibitors, rudimentary embryo or unsuitable growing media. So in this work we particularly emphasize in the last cause i.e. improper developing media. Many earlier works suggests that if the media is good enough than the seed development may be proper and dormancy can be relieved. So here tea (left over tea after being used) has been taken as a major media constituent to check its effect on papaya seed growth and development. The compost of tea has been found to be containing enormous mass of

How to cite this article: Mandal, P. and Das, A. 2021. Effect of Tea as a Potting Substrate on Germination and Seedling Growth of Papaya Seeds. Int. J. Ag. Env. Biotech., 14(04): 495-499.

Source of Support: None; Conflict of Interest: None $\infty$ 
good microorganisms (protozoa, bacteria, fungi), has the ability to reduce much soil born disease and increases the fertility of the soil and hence it is presently alluring many researchers towards it. Furthermore it has also been established that the tea compost has many nutrients of organic and inorganic basis. The compost tea also is able to assemble anaerobic as well as aerobic group of instrumental microbes (Ingham 2005; Scheuerell 2004; Scheuerell 2002). Therefore considering the importance of compost tea as a growing substrate, the present study on effect of tea as a potting substrate on germination and seedling growth of papaya seeds, was carried out.

\section{MATERIALS AND METHODS}

The present experiment was carried out in the Department of Horticulture, Institute of Agricultural Science, University of Calcutta during May, 2021. For this purpose fresh hybrid seeds named as Royal England were purchased from the nearby local market. The experiment was laid down as Completely Randomized Design (Gomez and Gomez 1984, Sheoran et al. 1998) replicated three times and tea was used as a main substrate in this experiment. Papaya seeds were sown in different pots that were filled with respective media $\left(\mathrm{T}_{1}\right.$ $100 \%$ tea $+0 \%$ soil, $\mathrm{T}_{2}-80 \%$ tea $+20 \%$ soil, $\mathrm{T}_{3}-70 \%$ tea $+30 \%$ soil, $\mathrm{T}_{4}-60 \%$ tea $+40 \%$ soil, $\mathrm{T}_{5}-50 \%$ tea $+50 \%$ soil and $\mathrm{T}_{6}-100 \%$ soil). Further data were collected on the basis of specific plant growth parameters such as germination percentage, number of leaves, length of leaves, length of roots, number of rootlets, increase in seedling length etc. Every day the pots had to expose out in the sun for 6-7 hours. Irrigations were done on daily basis in the evening until all the seeds germinate and then in an interval of 2 days. Other cultural practices like weeding and plant protection measures were done on daily basis. The appearance of root tip was considered as germination of seed. After 6 to 7 days most of the seeds were germinated. The major observation was done on 25, 30, 35 days after sowing.

\section{RESULTS AND DISCUSSION}

\section{Germination percentage}

Germination percentage was collected after completion of seed germination. The result showed in Table 1 revels that growth media had beneficial effect on the germination percentage of papaya seeds. Significantly the highest germination of $60 \%$ was observed in $\mathrm{T}_{3}$ and $\mathrm{T}_{5}$ (70\% tea $+30 \%$ soil and $50 \%$ tea $+50 \%$ soil). Whereas, the lowest germination percentage of $25 \%$ was observed on 25 DAS in $\mathrm{T}_{1}$ $(100 \%$ tea $+0 \%$ soil). Next on 30 DAS, the highest germination percentage of $80 \%$ was recorded in $\mathrm{T}_{2}$ (80\%tea $+20 \%$ soil) where as the lowest germination percentage of $35 \%$ was recorded in $\mathrm{T}_{1}(100 \%$ tea + $0 \%$ soil). Lastly highest germination percentage of $85 \%$ was observed in $\mathrm{T}_{4}(60 \%$ tea $+40 \%$ soil $)$ on 35 DAS and over all the lowest germination percentage of $20 \%$ was recorded in $\mathrm{T}_{1}(100 \%$ tea $+0 \%$ soil $)$ on 35 DAS.

Table 1: Effect of tea as potting media on germination percentage of papaya seeds

\begin{tabular}{llll}
\hline Treatments & 25 DAS & 30 DAS & 35 DAS \\
\hline $\mathrm{T}_{1}$ & 25 & 35 & 20 \\
$\mathrm{~T}_{2}$ & 45 & 80 & 80 \\
$\mathrm{~T}_{3}$ & 60 & 75 & 80 \\
$\mathrm{~T}_{4}$ & 45 & 75 & 85 \\
$\mathrm{~T}_{5}$ & 60 & 55 & 50 \\
$\mathrm{~T}_{6}$ & 55 & 50 & 55 \\
\hline $\mathrm{CD}$ & 7.343 & 12.719 & 8.993 \\
\hline Sem \pm & 2.357 & 4.082 & 2.887 \\
\hline
\end{tabular}

\section{Number of leaves}

It has been revealed from experimental results presented in Table 2 that the highest number of leaves, 6.0 per plant was initiated in maximum number of treatments i.e., $\mathrm{T}_{2}(80 \%$ tea $+20 \%$ soil), $\mathrm{T}_{4}(60 \%$ tea $+40 \%$ soil $), \mathrm{T}_{5}(50 \%$ tea $+50 \%$ soil $)$ and $\mathrm{T}_{6}$ (100\% soil) where as lowest number of leaves, 4.0 was initiated on 25 DAS in the treatment, $\mathrm{T}_{1}$ (100\% tea $+0 \%$ soil). Next reading was recorded on 30 Days after sowing where the highest number of leaves, 8.0 was observed in the treatment, $\mathrm{T}_{2}(80 \%$ tea $+20 \%$ soil), $\mathrm{T}_{3}\left(70 \%\right.$ tea $+30 \%$ soil), $\mathrm{T}_{4}(60 \%$ tea $+40 \%$ soil) $\mathrm{T}_{5}(50 \%$ tea $+50 \%$ soil $)$ and $\mathrm{T}_{6}(100 \%$ soil). The lowest number of leaves, 4.5 was seen on 30 days after sowing in the treatment $\mathrm{T}_{1}(100 \%$ tea $+0 \%$ soil). On 30 DAS most of the treatments gave positive response. Five out of the six treatments had significantly more number of leaves whereas only one treatment did not respond as well as the others. Last reading was recorded on 35 DAS where 
the highest number of leaves, 12.0 was observed in $\mathrm{T}_{2}(80 \%$ tea $+20 \%$ soil $)$ and in $\mathrm{T}_{5}(50 \%$ tea $+50 \%$ soil) whereas the lowest number of leaves, 6.0 was observed in $\mathrm{T}_{1}(100 \%$ tea $+0 \%$ soil $)$.

Table 2: Effect of tea as potting media on number of leaves of papaya seeds

\begin{tabular}{llll}
\hline Treatments & 25 DAS & 30 DAS & 35 DAS \\
\hline $\mathrm{T}_{1}$ & 4.0 & 4.5 & 6.0 \\
$\mathrm{~T}_{2}$ & 6.0 & 8.0 & 12.0 \\
$\mathrm{~T}_{3}$ & 5.5 & 8.0 & 10.0 \\
$\mathrm{~T}_{4}$ & 6.0 & 8.0 & 10.0 \\
$\mathrm{~T}_{5}$ & 6.0 & 8.0 & 12.0 \\
$\mathrm{~T}_{6}$ & 6.0 & 8.0 & 10.0 \\
\hline $\mathrm{CD}$ & 0.367 & 0.367 & - \\
\hline Sem & 0.118 & 0.118 & - \\
\hline
\end{tabular}

\section{Length of leaves}

The length of leaves also responded remarkably well under different treatments. The result showed significant difference among the treatments as shown in Table 3. Maximum length of collected mature leaves was recorded as $2.50 \mathrm{~cm}$ in $\mathrm{T}_{2}(80 \%$ tea $+20 \%$ soil $), \mathrm{T}_{4}(60 \%$ tea $+40 \%$ soil $), \mathrm{T}_{5}(50 \%$ tea + $50 \%$ soil), and $\mathrm{T}_{6}(100 \%$ soil) Where as the minimum length of leaves was $1.00 \mathrm{~cm}$ recorded on 25 DAS in $\mathrm{T}_{1}(100 \%$ tea $+0 \%$ soil $)$. In next observation on 30 DAS maximum length of leaves was recorded as $4.50 \mathrm{~cm}$ in $\mathrm{T}_{2}(80 \%$ tea $+20 \%$ soil $)$ and minimum length of leaves was recorded as $1.25 \mathrm{~cm}$ in $\mathrm{T}_{1}(100 \%$ tea $+0 \%$ soil). Last observation was done on 35 DAS where the maximum length of leaves was observed as $7.50 \mathrm{~cm}$ in $\mathrm{T}_{3}$ (70\% tea $+30 \%$ soil) whereas the minimum length of leaves was $2.00 \mathrm{~cm}$ in $\mathrm{T}_{1}(100 \%$ tea $+0 \%$ soil).

Table 3: Effect of tea as potting media on length of leaves $(\mathrm{cm}$.) of seedling of papaya seeds.

\begin{tabular}{llll}
\hline Treatments & 25 DAS & 30 DAS & 35 DAS \\
\hline $\mathrm{T}_{1}$ & 1.00 & 1.25 & 2.00 \\
$\mathrm{~T}_{2}$ & 2.50 & 4.50 & 5.75 \\
$\mathrm{~T}_{3}$ & 2.25 & 4.25 & 7.50 \\
$\mathrm{~T}_{4}$ & 2.50 & 4.25 & 6.75 \\
$\mathrm{~T}_{5}$ & 2.50 & 4.25 & 7.25 \\
$\mathrm{~T}_{6}$ & 2.50 & 4.25 & 5.00 \\
\hline $\mathrm{CD}$ & 0.184 & 0.410 & 1.146 \\
\hline Sem & 0.059 & 0.132 & 0.368 \\
\hline
\end{tabular}

\section{Length of roots}

From the tip of primary root to base of the hypocotyls is considered as the total length of root. It has been evident from experimental results presented in Table 4 that the highest root length of $7.00 \mathrm{~cm}$ was found in $\mathrm{T}_{2}(80 \%$ tea $+20 \%$ soil $)$ whereas the lowest length was found, $3.25 \mathrm{~cm}$ in $\mathrm{T}_{1}(100 \%$ tea $+0 \%$ soil $)$ on 25 DAS. In next observation highest root length of $11.75 \mathrm{~cm}$ was observed in $\mathrm{T}_{5}(50 \%$ tea $+50 \%$ soil $)$ and the lowest length of $3.50 \mathrm{~cm}$ was observed in $\mathrm{T}_{1}(100 \%$ tea $+0 \%$ soil $)$ on 30 DAS. In the last observation on 35 DAS the highest length of root was $17.00 \mathrm{~cm}$ in $\mathrm{T}_{5}$ (50\% tea $+50 \%$ soil) whereas the lowest, $5.25 \mathrm{~cm}$ was recorded in $\mathrm{T}_{1}(100 \%$ tea $+0 \%$ soil). Over all out of this major observation it was clearly seen that lowest number of length of roots were observed in $\mathrm{T}_{1}(100 \%$ tea $+0 \%$ soil $)$.

Table 4: Effect of tea as potting media on length of roots $(\mathrm{cm}$.) of papaya seeds

\begin{tabular}{llll}
\hline Treatments & 25 DAS & 30 DAS & 35 DAS \\
\hline $\mathrm{T}_{1}$ & 3.25 & 3.50 & 5.25 \\
$\mathrm{~T}_{2}$ & 7.00 & 6.25 & 12.50 \\
$\mathrm{~T}_{3}$ & 5.75 & 8.50 & 15.00 \\
$\mathrm{~T}_{4}$ & 6.50 & 11.25 & 13.50 \\
$\mathrm{~T}_{5}$ & 6.25 & 11.75 & 17.00 \\
$\mathrm{~T}_{6}$ & 6.00 & 8.50 & 12.50 \\
\hline $\mathrm{CD}$ & 0.880 & 0.800 & 1.336 \\
\hline Sem & 0.283 & 0.257 & 0.429 \\
\hline
\end{tabular}

\section{Number of rootlets}

Appreciable variations in rootlet numbers were observed in different replications. It has been noticed from experimental results presented in the Table 5 that the highest number of rootlets, 20.50 was observed in $\mathrm{T}_{4}$ (seed treated with $60 \%$ tea + $40 \%$ soil) on 25 DAS whereas the lowest, 7.00 was observed in $\mathrm{T}_{1}$ (seed treated with $100 \%$ tea $+0 \%$ soil). Next reading was taken on 30 DAS where the highest number of rootlets was 23.50, observed in $\mathrm{T}_{6}$ (seed treated with $100 \%$ soil) whereas the lowest 9.00 was observed in $\mathrm{T}_{1}$ (seed treated with $100 \%$ soil $+0 \%$ soil). Next highest number of rootlets, 25.00 was observed in $\mathrm{T}_{4}$ (seed treated with $60 \%$ tea $+40 \%$ soil) whereas the lowest, 11.50 was observed in $T_{1}$ (seed treated with $100 \%$ tea $+0 \%$ soil) on 35 DAS. 
Table 5: Effect of tea as potting media on number of rootlets of papaya seeds

\begin{tabular}{llll}
\hline Treatments & 25 DAS & 30 DAS & 35 DAS \\
\hline $\mathrm{T}_{1}$ & 7.00 & 9.00 & 11.50 \\
$\mathrm{~T}_{2}$ & 19.00 & 15.50 & 21.00 \\
$\mathrm{~T}_{3}$ & 17.00 & 19.00 & 23.00 \\
$\mathrm{~T}_{4}$ & 20.50 & 21.00 & 25.00 \\
$\mathrm{~T}_{5}$ & 16.50 & 22.50 & 23.50 \\
$\mathrm{~T}_{6}$ & 19.00 & 23.50 & 24.50 \\
\hline $\mathrm{CD}$ & 1.872 & 2.517 & 1.908 \\
\hline Sem & 0.601 & 0.808 & 0.612 \\
\hline
\end{tabular}

\section{Total length of seedlings}

Random seedling was selected for the measurement of final length of the seedling and for this purpose root length and shoot length were added. The root length was measured from the tip of the primary root to the base of hypostyle and shoot length was measured from the tip of the primary leaves to the base of hypostyle. It has been monitored from Table 6 that the highest length of the seedling, $13.00 \mathrm{~cm}$ was recorded in $\mathrm{T}_{2}$ (treated with $80 \%$ tea $+20 \%$ soil) whereas the lowest length of seedling, $6.25 \mathrm{~cm}$ was recorded in $\mathrm{T}_{1}$ (treated with $100 \%$ tea $+0 \%$ soil) on 25 DAS. Next reading was taken on 30 DAS where highest length of seedling, $18.00 \mathrm{~cm}$ was recorded in $\mathrm{T}_{4}(60 \%$ tea $+40 \%$ soil $)$ and lowest length of seedling, 6.50 was recorded in $\mathrm{T}_{1}(100 \%$ tea $+0 \%$ soil) Last reading was taken on 35 DAS where the highest length of seedling was 28.00 recorded in $\mathrm{T}_{5}$ (treated with $50 \%$ tea $+50 \%$ soil) whereas the lowest length of seedling was $9.25 \mathrm{~cm}$ observed in $\mathrm{T}_{6}(100 \%$ soil media).

Table 6: Effect of tea as potting media on total seedling growth $(\mathrm{cm}$.) of papaya seeds

\begin{tabular}{llll}
\hline Treatments & 25 days & 30 days & 35 days \\
\hline $\mathrm{T}_{1}$ & 6.25 & 6.50 & 9.25 \\
$\mathrm{~T}_{2}$ & 13.00 & 11.50 & 25.50 \\
$\mathrm{~T}_{3}$ & 12.25 & 17.25 & 26.00 \\
$\mathrm{~T}_{4}$ & 12.50 & 18.00 & 20.00 \\
$\mathrm{~T}_{5}$ & 11.75 & 17.75 & 28.00 \\
$\mathrm{~T}_{6}$ & 12.00 & 12.25 & 20.25 \\
\hline $\mathrm{CD}$ & 1.022 & 2.537 & 3.662 \\
\hline Sem & 0.328 & 0.814 & 1.176 \\
\hline
\end{tabular}

By analyzing the result, it is revealed that different treatment media used in this study had different impact on the selected parameters of growth and seedling performance. With respect to highest percentage of germination i.e., $85 \%$ was observed in $\mathrm{T}_{4}(60 \%$ tea $+40 \%$ soil $)$ on 35 DAS. The results clearly indicated that combination of growing media has played a significant role for inducing early germination in papaya seeds. Similar work has been done by Parasana et al. (2012) in mango, where different growing media showed significant increase in germination performance. Remarkable variation was observed in case of number of leaves under different treatments. A high noticeable difference was observed from week 4 to week 5 . This was in accordance of earlier work of Sudeshika et al. (2018) where the experiment was about the effect of different rooting media in growth of carrot (Daucus carota) and it was established that number of leaves can be influence by the nutrition supplied from the growth media. The length of leaves also escalated and it matches related work of Kilic et al. (2018) about the effect of different substrates on yield and fruit quality of tomato. Papaya seedlings showed appreciable effect on the length of root and number of rootlets. Compost tea extracts used as an organic fertilizer had beneficial effects on plant growth and also helped to increase the length of roots. Yadav et al. (2012) obtained similar result in acid lime using soil: sand: vermi compost: vermiculite: coco peat (1:1:1:1:1) media. The total seedling length expanded. This may be due to the planting media having effective physical properties and sufficient water holding capacity leading to vigorous growth of the seedling. Same results were found in the experiment conducted by Raj Kumar et al. (2016).

\section{CONCLUSION}

The seedlings grown in $\mathrm{T}_{4}(60 \%$ tea $+40 \%$ soil $)$ and $\mathrm{T}_{5}$ (50\% tea $+50 \%$ soil) were comparison wise better in germination percentage, number of leaves, length of leaves, number of rootlets, length of root, total length of seedling but the treatment of $\mathrm{T}_{1}(100 \%$ tea $+0 \%$ soil) did not responded as like other treatments and even the germination of seed took place here, significantly very late. So it is understandable, from the total follow up that the tea responded best in almost half and half combination with soil where as the seedling did not do well when the tea was taken alone as a growing media. 


\section{REFERENCES}

Gomez, K.A. and Gomez, A.A. 1984. Statistical Procedures for Agricultural Research (2 ${ }^{\text {nd }}$ Ed.). Wiley-Inter Science Publication,) New York, USA.

Ingham, E. 2005. Compost Tea Brewing Manual. Soil Foodweb Inc., Corvallis, OR. http://www.soilfoodweb.com Last Accessed on $7^{\text {th }}$ February,2021

Kılic, P., Aktas, H. and Erdal, I. 2018. Effect of different substrates on yield and fruit quality of Tomato grown in soilless culture.2. 249-261. 10.14597/INFRAECO. 2018. 2.1.016.

Pandit, V.K., Nagarajan, S. and Sinha, J.P. 2001. Improving papaya (Carica papaya) seed germination and seedling growth by pre-sowing treatments. Indian J. Agric. Sci., 71(11): 704-706.

Parasana, J.S., Ray, N.R., Satodiya, B.N., Patel, K.A. and Panchal, G.P. 2012. Effect of mixture of growing media on germination and seedlings growth of different mango (Mangifera indica L.) cultivars under net house conditions, Asian J. Hort., 7(2): 409-41.

Raj Kumar, Shamet, G.S., Alam, N.M. and Jana, C. 2016. Influence of Growing Medium and Seed Size on Germination and Seedling Growth of Pinus gerardiana Wall. Compost Sci. Util., 24(2): 98-104.

Rana, G., Deb, P., Dowarah, B. and Sushmitha, K. 2020. Effect of Seed pre treatment on Seed Germination and Seedling Growth of Papaya. Int. J. Curr. Microbiol. App. Sci., 9(04): 1066-1071.
Reyes, M.N., Perez, A. and Cuevas J. 1980. Detecting endogenous growth regulators of sarcotesta, scleroterta, endosperm and embryo by paper chromatography in fresh and edged seeds of two varieties of papaya. $J$. Agricultural University, Pure/o Rico, 45: 188-90.

Scheuerell, S.J. and Mahaffee, W.F. 2002. Compost Tea Principals and Prospects for Plant Disease Control. Compost Sci. Util., 10(4): 313-338.

Scheuerell, S.J. and Mahaffee, W.F. 2004. Compost Tea as a Container Medium Drench for Suppressing Seedling Damping-Off Caused by Pythium ultimum. Phytopathology, 94: 1156-1163.

Sheoran, O.P., Tonk, D.S., Kaushik, L.S., Hasija, R.C. and Pannu, R.S. 1998. Statistical Software Package for Agricultural Research Worker. Recent Advances in information theory, Statistics and Computer Applications by D.S. Hooda and R.C. Hasija, Department of Mathematics Statistics, CCS HAU, Hisar, pp. 139-143.

Sudeshika, W.A.A., Pradheeban, L., Nishanthan, K. and Sivachandiran, S. 2018. Effect of different rooting media on growth and yield performances of carrot (Daucus carota). Int. J. Agron. Agri. Re., 12(4): 31-38.

Yadav, R.K., Jain, M.C. and Jhakar, R.P. 2012. Effect of media on growth and development of acid lime (Citrus aurantifolia Swingle) seedling with or without Azotobacter. Afr. J. Agric. Res., 7(48): 6421-6426. 
